\title{
Aqueous Media Deprotection of Ketoximes with Ammonium Persulfate
}

\author{
G. H. Imanzadeh, ${ }^{\star}$ M. R. Zamanloo, H. Eskandari, and A. R. Banaei ${ }^{\dagger}$ \\ College of Chemistry, Mohagheghe Ardebili University, Ardebil 179. Iran. "E-mail Imanzad20o0(d)y ahoo.com \\ "Payam-Noor University of Ardebil, 55135, Ardebil, Iran \\ Recened August 12, 2005
}

Key Words : Ketoximes, Deoximation. Aqueous media, Ammonium persulfate

Oximes are very useful for protecting groups in organic synthesis.' These highly crystalline compounds can be prepared from carbonyl and non carbonyl compounds. ${ }^{2}$ The regeneration of carbonyl compound from oximes provides an alternative method for the preparation of these compounds. The classical method for regeneration of carbonyl compounds from oximes reqire strongly acidic conditions, which is not suitable for acid sensitive compounds. ${ }^{3}$ ln order to avoid this, many oxidative deoximation methods have been developed in recent years. ${ }^{4-4}$

Ammonium persulfate is an inexpensive and readily accessible oxidizing agent. It is commonly used in industry for bleaching ${ }^{10}$ and for wastewater treatment." Ilowever, only sporadic literature is available that describes its applications in organic synthesis, the oxidations of alkenes, ${ }^{12}$ substituted aromatics, ${ }^{13}$ cyclization ${ }^{14}$ and deoximation under strenuous conditions using sulfuric acid. ${ }^{15}$

Synthetic chemists continue to explore new methods to carry out chemical transformations. One of these new methods is to run reactions in aqueous media. Organic reactions in water, without the use of any harmful organic solvents, are of great current interest, because water is an easily available, economical, safe and environmentally benign solvent. ${ }^{16}$ In continuation of our ongoing program to develop environmentally benign methods in the absence of organic solvent, ${ }^{17-22}$ we now wish to report that ammonium persulfate deoximates ketoximes to the parent ketones cleanly and in good yield in an aqueous media. This reagent oxidizes aldehydes to acids, so deoximation of aldoximes is unlikely to be useful.

Dissolution of ammonium persulfate in water and subsequent reaction with ketoximes under stirring at room temperature or reflux gave the corresponding carbonyl compounds in good yields. Table 1 contains a summary of the results we have obtained for variety of ketoximes. The synthetic value of these results is apparent when it is noted that such reactions in the past have usually been achieved by the use of activated ammonium persulfate. ${ }^{15}$ Even the sterically hindered ketoximes were successfully deoximated in excellent yields (entries 1 and 9). This reaction does not require an activation procedure or the use of expensive equipment or materials.

Table 1. Deoximation of ketoximes with ammonium persulfate

\begin{tabular}{|c|c|c|c|c|c|c|c|}
\hline \multirow{2}{*}{ Entry } & \multirow{2}{*}{$\mathrm{R}_{1}$} & \multirow{2}{*}{$\mathrm{R}_{\beth}$} & \multirow{2}{*}{ Tïne (h) } & \multirow{2}{*}{ Temperature $\left({ }^{\circ} \mathrm{C}\right)$} & \multirow{2}{*}{ Yields $(\%)$} & \multicolumn{2}{|c|}{$\mathrm{Mp}(\mathrm{C})$ or $\mathrm{Bp}(\mathrm{C}) / \mathrm{T}$ orr } \\
\hline & & & & & & Found & Reported $^{23}$ \\
\hline 1 & $\mathrm{Ph}$ & $\mathrm{Ph}$ & 1.5 & 100 & 98 & $48-49$ & $48.5-49$ \\
\hline 2 & Ph & $\mathrm{CH}_{3}$ & 1.0 & 100 & 94 & $200-202 / 760$ & $202 / 760$ \\
\hline 3 & 4-BrPh & $\mathrm{CH}_{3}$ & 1.0 & 25 & 99 & $49-51$ & $50-51$ \\
\hline 4 & $2-\mathrm{C}_{6} \mathrm{CH}_{4}$ & $\mathrm{CH}_{3}$ & 2.0 & 100 & 80 & $228-230 / 760$ & $227-230 / 760$ \\
\hline 5 & $4-\mathrm{MeC}_{6} \mathrm{H}_{4}$ & $\mathrm{CH}_{3}$ & 1.5 & 100 & 93 & $227-287760$ & $226 / 760$ \\
\hline 6 & 4-C $\mid \mathrm{C}_{6} \mathrm{H}_{4}$ & $\mathrm{CH}_{3}$ & 2.0 & 100 & 80 & $238-239 / 760$ & $237 / 760$ \\
\hline 7 & 3.4-( $\mathrm{MeO})_{2} \mathrm{C}_{6} \mathrm{H}_{5}$ & $\mathrm{CH}_{3}$ & 1.0 & 100 & 88 & $44-46$ & $46-49$ \\
\hline 8 & $\mathrm{Ph}$ & $\mathrm{PhCO}$ & 9.5 & 100 & 97 & 95 & 95 \\
\hline 9 & & & 8.0 & 25 & 91 & $157 / 760$ & $155 / 760$ \\
\hline 10 & & & 0.5 & 100 & 94 & - & - \\
\hline 11 & & & 1.0 & 100 & 87 & $133 / 760$ & $131 / 760$ \\
\hline
\end{tabular}

"Yiclds refer to isolated products. 
<smiles>CC(=N)c1ccccc1</smiles><smiles>[OH2+]C(P)c1ccccc1</smiles>

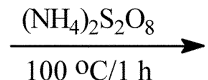

Figure 1
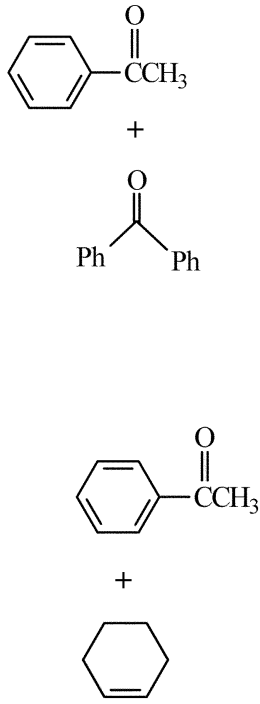
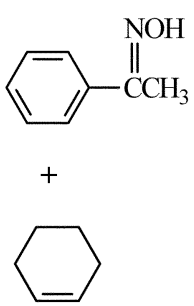

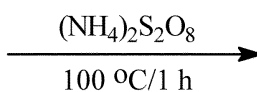

Figure 2
Our tries to deoximation of ketoxime in the presenee of alcohol by this method was unsuceessful. When equimolar solution of benzhydrol and acetophenone oxime was treated with ammonium persulfate a mixture of benzophenone and aectophenoe was obtained (Fig. 1).

We also tried the reaction of acetophenone oxime with ammonium persulfate in the presence of cyclohexene under the same reaction conditions. Surprisingly, TLC analysis indicated that the ketoxime was exclusively oxidized to ketone and the reagent was ineffective in oxidizing $\mathrm{C}=\mathrm{C}$ double bond (Fig, 2). Further investigation on the applications of ammonium persulfate in oxidation of other functional groups in acpucous media is ongoing in our laboratories.

In conclusion, we have developed a new and simple method for deprotection and deoximation of ketoximes. We hope this method will be useful to organic chemists because of, the simplicity of work-up, selectivity, readily available of oxidant, low cost, high yield and avoiding the use of flammable an environmentally hazardous solvent.

\section{Experimental Section}

All yields refer to isolated product. Thin layer chromatography (TLC) was carried out using glass sheets precoated with silica gel 60F. Melting points were determined on an Electro thermal Gallen Kamp apparatus and uncorrected. ${ }^{2} H N M R$ spectra were recorded on a Varian EM-390 90 $\mathrm{MHz}$. IR spectra were obtained using a Shimadzu IR-435 spectrometer. The purity of products was determined by GC and 'HNMR spectroscopy, and comparing with authentic samples.

General procedure. In a $50 \mathrm{~mL}$ round bottomed flask, ketoxime $(1.0 \mathrm{mmol})$ was added to ammonium persulfate (1.5 mmol) that was dissolved in $10 \mathrm{~mL}$ water and the suspended reaction mixture was good stirred at room temperature or under gentle reflux for the designated time (Table 1). After the completion of reaction (monitored by TI.C) the product was extracted into $20 \mathrm{~mL}$. of ether and dried over anhydrous magnesium sulfate. The solvent was removed by evaporation under reduced pressure to yicld the product.

Acknowledgement. We thank to the Mohagheghe Ardebili University, and Istahan University of Technology Councils for the partial support to this work.

\section{References}

I. Corey, E. J.; Hopkins, P. B.; Kim. S.; Yoo, S.; Nambiar, K. P.; Falk. J. R. J. Am. Chem. Soc. 1979, 101, 7I3I.

2. Barton, D. H. R.; Beaton, J. M.; Jeller, L. E.; Pechet, M. M. J. Am Chent. Str. 1961, 83,4076.

3. Hersberg, Г. B. J. Org. Che'm. 1984, 49, 542

4. Satish, S.; Kalyanam. N. Chem. Ind. 1981, 809.

5. Pines, S. I 1; Chemerda, J. M.; Kotlowoski, M. A. J. Org. Chem. 1966, 31, 446.

6. Drabowicz, J. Simmesis 1980,125

7. Hajipour, A. R.; Mahboubkhah, N. J. Chem. Research (s) 1998, 123.

8. Rao, C. (i.: Radhakrishna, A. S.; Singh, B. B.; Bhatnagar, S. P. Synthesis 1983, 808 .

9. Khazaei, A.; Amini, A. A. J. Braz. Chrm. Soc. 2005, 16, 874.

10. Kazunobu, N.; Kanetsugu, T. Jenen Pentent Appl. 7196,636; Chem. Abst: 1974, 80, $16373 \mathrm{~m}$.

11. Zumbunn. J. P. Trib. SBFDFAC 1973, 26, 332; Chem. Absts. $1974,80,1917 \mathrm{k}$.

12. Fristad, W. E.; Peterson. J. R. Totrahedron Lett. 1983, 24, 4547.

13. Clerici, A.: l'orta, O. Cam. J. Chom. 1980, 56, 2117.

14. Tryupisı, V. M.; Almaev, R. Kh.; Bikkulov, A. Z.; Kalinina, V. M.; Baiguzina, G. A. USSR SU I, 198.07; Chem. Absrr. 1986, 105, $152926 \mathrm{i}^{\circ}$.

15. Brooks, S. Gi.; Evans, R. M.; Green, (j. F. I I.: I Junt, J. S.; Long, A. G; Mooney, B.; Wyman, L. J. J. Chem. Soc. 1958, 4614.

16. Subhash, P.; Pritis, S. Tetrahedron Lett. 2004, 45, 3161.

17. Hajipour; A. R.; Mallakpour, S. E.; Imanzadeh, G. H. Chemist'y Lett. 1999,99

18. I Jajipour. A. R.; Mallakpour, S. Г.:; Imanzadeh. G. HI. I. Chent. Reserarch(s) 1999, 228.

19. I ajipour, A. R.; Mallakpour, S. E.; Imanzadeh, (i. I1. Indian J. Chem. Sect. B 2001, 40B, 250.

20. Haijpour, A. R.: Mallakpour; S. E.; lmanzadeh, G. H. Indicm J. Chem. Sect, B 2001, 40B, 237.

2I. IJajipour, A. R.; Mohammadpoor Baltork, I.; Imanzadch, G. Il. Symth. Commmt 1999, 29, 1697.

22. Chiaci, M.: Imanzadel, (3. H]. Sinth. Commun. 1998, 28, 2275.

23. Aldrich Catalogue/Handbook of fine Chemicals, 1990-91. 